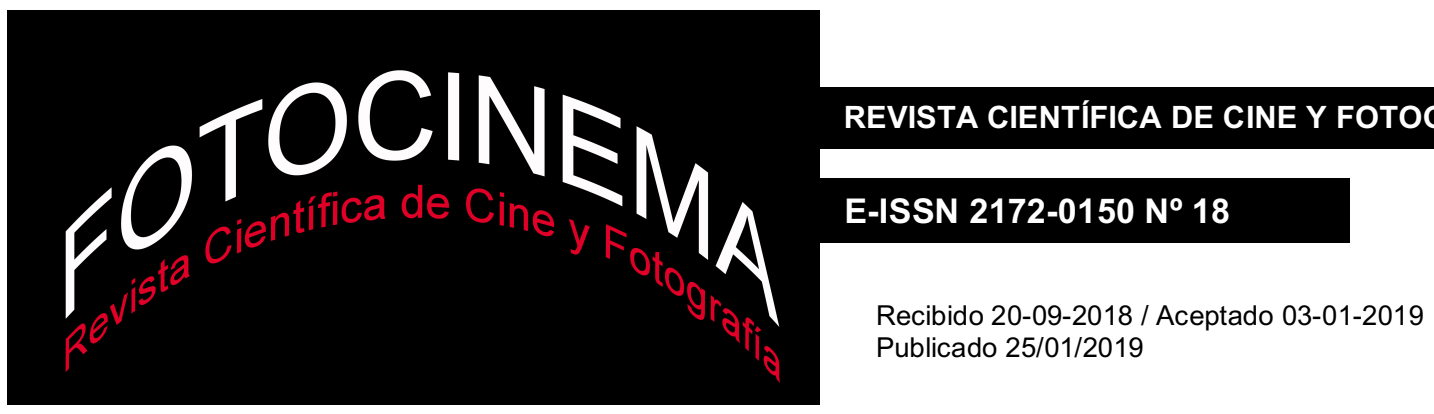

\title{
El globo de texto como transposición del diálogo del cómic al cine en ¿Quién quiere matar a Jessie? (Kdo Chce Zabít Jessii?, Václav Vorlíček, 1966)
}

\author{
Speech balloons as transposition of comic dialogue to cinema in \\ Who wants to Jessie? (Kdo Chce Zabít Jessii?, Václav Vorlíček, 1966) \\ Luis E. Froiz Casal \\ Universidade de Santiago de Compostela, España \\ lfroiz@hotmail.com
}

\begin{abstract}
Resumen:
¿Quién quiere matar a Jessie? (Kdo Chce Zabít Jessii??, Václav Vorlíček, 1966) es una película que, desde la comedia y las formas más propias del cine de entretenimiento ligero, sirve como planteamiento de comunicación entre las especificidades del lenguaje del cómic y del cine. En ella, los personajes aparecidos en un tebeo para adultos cobraban forma corpórea en la realidad objetiva diegética, destrozando el mundo y comunicándose a través de bocadillos de texto. La relación entre las formas de diálogo de ambas artes narrativas se convierte en un juego que nos obliga a repensar la representación gráfica del texto y del diálogo en el cine, así como las diferencias narrativas que presentan, debido a la diferenciación en la forma síncrona o temporal, el noveno y el séptimo arte. Del mismo modo, la representación de personajes incapaces de emitir sonidos, comunicándose solo a través de texto escrito en pantalla, ejecuta una suerte de reflexión sobre el cine silente y la evolución hacia el cine sonoro, enfrentando dos momentos históricos de la técnica cinematográfica.
\end{abstract}

\begin{abstract}
:
Who Wants to Kill Jessie? (Kdo Chce Zabit Jessii?, Václav Vorlíček, 1966) is a film that, from the comedy and from forms closer to the light entertainment cinema, serves as an approach to the communication between the language specificities of comic books and cinema. In the film, the characters that appeared in an adults' comic book took on corporeal form in the objective diegetic reality, destroying the world and communicating through text balloons. The relationship between the dialogues form from both narrative arts becomes a game that makes us rethink the graphical representation of text and dialogue in cinema, as well as the narrative differences that are shown by the seventh and ninth art due to the differentiation in synchronous and temporal forms. In the same way, the representation of characters incapable of emitting sounds, who communicate only through written text on screen, performs a though about silent movies and its evolution towards sound film, facing two historical moments of cinematographic arts.
\end{abstract}

Palabras clave:

Cine checoslovaco; Václav Vorlíček ;¿Quién quiere matar a Jessie?; cómic y cine.

Keywords:

Czechoslovak film; Václav Vorlíček; Who Wants to Kill Jessie?; Comic and Cinema. 


\section{Introducción}

Dentro del cine checoslovaco de los años 60 es costumbre hablar de la Nová Vlna, la Nueva Ola que llevaron adelante directores como Miloš Forman, Věra Chytilová, Jiř́i Menzel, Jan Němec o Juraj Jakubisko, por citar algunos de los ejemplos más destacados. Un movimiento cuya importancia a nivel mundial, como Peter Hames explicaba,

fue establecida por una sucesión de premios en festivales internacionales durante los años 60 y una ruptura crítica y comercial en los mercados occidentales que culminó en los Óscar de Hollywood ganados por La Tienda en la Calle Mayor (Obchod na Korze) en 1965 y Trenes Rigurosamente Vigilados (Ostře Sledované Vlaky) en 1967 (Hames, 1985, p. 1).

Sin embargo, no solo fue en el sector más cercano a las corrientes de vanguardia y del cine-arte donde se vivieron aires de libertad y de revolución temática y formal dentro de la creación cinematográfica checoslovaca. En el cine más comercial y sobre todo en las comedias, podemos -y debemos- buscar y encontrar también un caldo de cultivo para la experimentación de fondo y de forma.

Es precisamente en este campo más cercano al público y al cine como espectáculo de masas que surgen obras como las enormes Happy End (Oldřich Lipský, 1967) o El Gato de Cassandra (Až Přijde Kocour, Vojtěch Jasný, 1963), la primera de ellas efectuando un salto al vacío narrativo al estructurarse en torno a mostrarnos toda la acción en sentido contrario al habitual a través de la moviola y la segunda proponiéndonos una divertida y poética comedia que planta sus raíces estéticas directamente en los principios del Teatro Negro $^{1}$ y el realismo mágico.

De este modo, influenciados por este aire de libertad absoluta en la narración y en las propuestas formales que los jóvenes directores recién salidos de la FAMU2 estaban llevando a cabo, los directores más comerciales del cine del país

\footnotetext{
${ }^{1}$ El Teatro Negro (Černé Divadlo) es una forma teatral común en la República Checa (y especialmente en su capital, Praga), basado en una iluminación con luz negra y elementos fosforescentes. De este modo, las representaciones se basan principalmente en trucajes que aprovechan el efecto de sombras y luces para crear sensaciones fantasmagóricas.

2 FAMU (Filmová a televizní fakulta Akademie múzických umění v Praze) es la Escuela de Cine y Televisión de la Academia de Artes Escénicas de Praga. Nacida en 1946, está considerada una de las escuelas de cine más importantes del mundo. En los años 60, sus aulas fueron el caldo de cultivo para el nacimiento de la Nová Vlna, siendo la mayoría de los directores englobados por el movimiento licenciados de la escuela entre 1960 y 1968.
} 
centroeuropeo se sumaron a los riesgos. Como señala Williams hablando de Vaclav Vorlíček, director de la cinta en la que se centra la presente investigación, los críticos en Checoslovaquia, por lo general, no han considerado a Vorlíček parte de la Nueva Ola Checa, etiquetando su trabajo como conformista, apolítico y escapista. Sin embargo, estaba claramente influenciado por el mismo clima artístico de mediados de los 60 que influyó en la Nueva Ola, particularmente en lo que respecta a la fantasía (Williams, 2017, p. 147).

Es cierto que, a grandes rasgos y sobre todo si lo comparamos a la Nová Vlna, se trata de un director cuyos films adolecen de una falta de compromiso social y político. Sin embargo, profundizando más sobre ellos, podemos apreciar que se une a sus coetáneos a través de comedias que destacan por plantear, como es el caso de ¿Quién quiere matar a Jessie?, sátiras que juegan con los principios formales del cine y giran en torno a las convenciones de la cultura popular dominante, hundiendo sus cimientos como parodias en las campañas promovidas por las autoridades en los años 30 y 40 contra la "literatura basura" (Mareš, 2014, p. 16).

Hemos citado anteriormente a Lipský, y debemos volver a hacerlo, puesto que pocas obras ejemplificarían tan bien esta reflexión humorística sobre lo popular como Joe Kola Loca (Limonádový Joe Aneb Konská Opera, 1964), donde junto con Jiř́ Brdečka -el autor de la obra original, además de ser uno de los animadores más importantes de la historia del cine checo-, Lipský planteaba una parodia del western llena de guiños al cine silente y a la cultura americana, así como a las ideas del macho alfa en el cine del oeste clásico, a través de un cowboy que llegaba a la ciudad para promover el consumo de bebidas no alcohólicas.

De este aire de libertad creativa, formal y temática, como decimos nace ¿Quién quiere matar a Jessie?, una comedia que comparte con Joe Kola Loca la presencia de la actriz Olga Schoberová, amén de actores habituales de la comedia checa como Vladimír Menšík o Karel Effa. También, en unión con el western bufo de Lipský, presenta un gusto especial por la narrativa visual del cine silente, así como por los recursos cómicos del slapstick antes que por el intento de generar una comedia que pudiésemos encuadrar en los 60, si la evolución narrativa y estilística fuese un continuum rectilíneo. Una obra cuyo principal atractivo a nivel superficial es la introducción de personajes que hablan solamente a través de 
globos de texto, aunque intentaremos profundizar en las diferentes capas de significación que este ejercicio de estilo provoca.

\section{Objetivos y metodología}

En el presente estudio pretendemos analizar cómo el film de Vorlíček se estructura, primero, desde la novedosa idea de no adaptar un cómic al cine, sino de llevar personajes de cómic a la vida real y confrontar el problema de los diálogos escritos de los personajes de cómic con el tiempo continuo y no estático de una película. Una base que nos crea por un lado una sensación de extrañamiento, y por el otro nos permite establecer una serie de reflexiones ya no solo sobre la diferencia existente entre los dos medios, sino sobre la propia especificidad que se crea a partir de la forma del diálogo y de la escritura en pantalla.

Del mismo modo, trataremos de explicar cómo a través de la alteración de los códigos habituales del cine para recoger una idea del cómic, la obra cinematográfica mira a los orígenes silentes del medio y con ello, a la propia génesis común de ambas artes, observadas en un principio de un modo cercano al tratarse de industrias narrativas cuyo éxito entre el gran público fue coetáneo y con préstamos no solo temáticos sino incluso formales, estereotípicos y situacionales. Ideas que, si bien no se explicitan en la obra de Vorlíček, sí son fundamentales para su análisis y la comprensión profunda de su capacidad de sorpresa y comicidad.

Para llegar a estos objetivos, la base metodológica escogida es la del análisis de contenido y el estudio historiográfico. Pretendemos desgranar el interior del film comparándolo con otras representaciones similares y repensar la significación y función de los globos de texto dentro de la narrativa de Vorlíček en la película escogida. Del mismo modo, queremos comprender la importancia de la experimentación que propone el director checo dentro de la realidad histórica en la que nace.

Para nuestro análisis, hemos procedido al visionado de la obra para estudiar la estructura narrativa de la misma y así comprender las diferentes relaciones entre la historia y el cine coetáneo, repensando las posibilidades exploradas para la 
convergencia del cómic y el cine. Después, analizamos la función que cumplen los diálogos escritos en la pantalla a través de los globos de texto. De este modo, intentamos recoger la novedad estilística más reseñable en la superficie de ¿Quién quiere matar a Jessie? -la introducción de los globos de texto como elemento comunicativo en el cine- y comprender exactamente qué aporta a nivel estilístico, formal y narrativo.

Pretendemos, con esto, reflexionar primero sobre la obra en su conjunto para después centrarnos en los aspectos novedosos que resultan más llamativos. Así, trataremos de comprender cómo la palabra escrita con origen en el cómic puede resultar una herramienta interesante para la narración audiovisual desde la idea escogida por Vorlíček.

\section{La representación del cómic en el cine}

La relación entre el cine y el cómic es tan antigua como el cine mismo. Y podríamos decir, tomando determinadas licencias historiográficas, que casi como el cómic. Autores como McCLoud (1993/1995, pp. 10-23) han encontrado -no sin razón- ciertos orígenes intencionales de la narrativa secuencial en grabados precolombinos, en el tapiz de Bayeux procedente del s. XI o incluso en la pintura egipcia. Por otro lado, la génesis de lo que en la actualidad definimos como cómic está, como defienden el propio McCloud (1993/1994, p. 17) y otros autores como García (2010, p. 22), en el trabajo de Rodolphe Töpffer en la década de 1820 -al que incluso Goethe alababa por la idea desarrollada y sus posibilidades-. Pese a ello, no debemos obviar que fueron las publicaciones de Richard Felton Outcault, Rudolph Dirks o Bud Fisher en la prensa americana de finales del s. XIX “quienes iniciaron la tradición que habría de seguir el cómic americano, europeo y japonés durante la pasada centuria” (García, 2010, p. 28).

Así, tomando el origen del cómic más en su popularización como medio que en su génesis primigenia, podemos revisar retrospectivamente las primeras adaptaciones de cómics al cine y encontrarnos con que la seminal comedia slapstick de los hermanos Lumière El Regador Regado (L'arroseur Arrosé, Louis Lumière, 1895) ya se trataba, como señala Burke (2015, p. 3), de la adaptación de una tira con un chiste gráfico que podíamos encontrar en diversos autores. Un primer ejemplo podría ser Ein Bubenstreich, publicada por Hans Schließmann 
en Fliegende Blätter el 15 de agosto de 1886 o Fait Divers, de A. Sorel, publicada por La Caricature el 12 de marzo de $1887^{3}$, que se asemejan bastante a la escena filmada por Louis Lumière.

Teniendo en cuenta esta influencia inicial, no es de extrañar que, finalmente, en la actualidad las adaptaciones de cómic se hayan vuelto omnipresentes en el cine comercial gracias a las nuevas técnicas de animación y filmación. Pero la tendencia, que en el s. XXI se ha convertido en una constante dentro del cine más accesible y se ha mostrado como una de las principales razones críticas que recibe la industria hollywoodiense, se mantuvo puntualmente a lo largo del s. XX. Autores como Davis (2017, p. 251) han llegado a decir que "la idea de que los personajes de cómic nunca han sido más frecuentes en Hollywood es una falacia” ya que desde siempre han estado ahí, aunque probablemente no en tantas producciones de alto nivel. Para estas adaptaciones surgidas a lo largo de la historia del cine ha habido que plantear, eso sí, la asunción de que se trata de dos medios con una diferencia básica:

mientras que un film se presenta como la combinación de imágenes sucesivas en el espacio fijado de la pantalla, con una imagen retrocediendo en la memoria del espectador al ser suplantada por la siguiente, los cómics operan en un sistema de co-presencia, en el que existen dentro del espacio de la página o de la doble página, expandidas simultáneamente (Beaty, 2011, p. 108).

Así, la adaptación de una base narrativa en términos de cine de acción y aventuras que se acercaría bastante a la tónica actual ya la podíamos ver en Superman (Richard Donner, 1978). Otra opción totalmente opuesta para la adaptación es la pretensión de respetar los tiros de cámara y los experimentos visuales con la luz y el color de Sin City (Frank Miller, Robert Rodriguez, 2005). También es obligatorio recoger la aproximación a través de la estructuración en pequeñas historias de terror de Creepshow (George A. Romero, 1982), o la adaptación directamente animada, incluyendo el mismo tipo de dibujo, en Akira (Katsuhiro Ôtomo, 1988) o muchos de los álbumes adaptados de Astérix o Tintín4. Incluso,

3 Es posible consultar una recopilación de "regadores regados" en la web Töpfferiana, especializada en información sobre los orígenes del cómic: http://www.topfferiana.fr/2010/10/arroseurs-arroses/. Consultado el 18/o9/2018.

4 Aunque en Astérix habría que repensar también las adaptaciones de imagen real y en Tintín de su adaptación como cine de animación 3D, así como otra de imagen real estrenada en 1961 y otra de animación stop-motion de 1947. 
en los últimos años estamos viendo una cierta revolución nacida de la época digital a través de la aparición de lo que se ha venido a llamar Motion Comics, un híbrido entre el cómic y el cine de animación que, recogiendo los dibujos del cómic, separándolos por capas y jugando con las opciones que esto permite de cara a animarlos, renueva las opciones narrativas del formato con las ventajas de lo digital (Smith, 2015, pp. 4-9). Con todas estas variantes, podemos ver una enorme divergencia en las estéticas de aproximación de un lenguaje narrativo al otro. Sin embargo, todas ellas siguen una tónica establecida que las separa de la película que nos ocupa en esta investigación.

Primero, está el hecho de que las obras citadas son adaptaciones directas de cómics o de los universos de esos cómics en la pantalla y no la introducción de un mundo de cómic en el mundo real. Por otro lado, debemos tener en cuenta la búsqueda de un lenguaje y una estética cinematográfica cuando se trata de imagen real, al margen del cómic de origen (con la salvedad de Sin City, que sin embargo sí lo buscaba en la narrativa, igual que lo haría poco después The Spirit (Frank Miller, 2008), en una onda excesivamente similar). Quizás de todos los ejemplos que podríamos citar, la que más se aproximase a ¿Quién quiere matar a Jessie? fuese el Batman encarnado por Adam West, Batman: La Película (Batman: The Movie, Leslie H. Martinson, 1966), con su tono de parodia autoconsciente y la sempiterna -y homenajeada en múltiples ocasionesintroducción de onomatopeyas en los golpes, interrumpiendo la acción para provocar el acercamiento al formato cómic. Una introducción de onomatopeyas que autores como Fontaine Rousseau (2014, p. 20) han considerado que "puede parecer hoy decididamente naif, por no decir francamente reductiva”. Sin embargo, Vorlíček apunta a otro objetivo en su película, alejado de la idea propuesta por Martinson y lo que busca es, directamente, establecer una comparativa del medio fílmico con el tebeo a través de la base de desarrollo de sus narrativas y sobre todo de sus diálogos.

También partiendo de la diferencia entre ambos medios, autores como Lefèvre han estudiado el problema de la transposición del cómic al cine, planteando con las siguientes palabras la dificultad que se nos presenta:

hay cuatro problemas principales en la adaptación de cómics al cine y tres de ellos se relacionan con el medio del cómic mismo: las viñetas están colocadas en una 
página, las viñetas son dibujos estáticos y un cómic no hace ruido ni sonidos

(Lefèvre, 2007, p. 3).

Es curioso, entonces, que precisamente sea una de las soluciones a los problemas que limitarían al cómic como medio lo que Vorlíček escoge como representación, como elemento base que define a sus personajes. Así, lo que hace es emplear esa falta de capacidad de emisión de sonidos para conseguir la estética de cómic a través de imprimir en pantalla los diálogos de algunos de los personajes de la historia.

\section{Forma estructural del film}

La base sobre la que se sostiene ¿Quién quiere matar a Jessie? es sencilla. Retomando ideas del cómic americano y de los estudios de psiquiatría más básicos, así como planteamientos propios de la ciencia ficción de serie $\mathrm{B}$, recoge personajes sacados del cómic para introducirlos en la realidad cotidiana a través de los sueños, con la especificidad de que estos personajes no son capaces de articular diálogos de manera auditiva, sino que mantienen para comunicarse el característico globo que tendrían de haber seguido dentro del cómic. Esta característica, sobre la cual se estructura toda la idea innovadora de la estética del film, es aprovechada por Václav Vorlíček -quien además de dirigir había escrito el guion junto al poeta y dramaturgo Miloš Macourek- para introducir un humor alocado que se desarrolla a través de colocar a los personajes en un mundo totalmente externo al suyo, provocando un sentimiento de extrañamiento constante en el espectador, obviamente poco habituado a la idea de tener una serie de personajes que no hablan si no es a través de diálogos escritos en la pantalla.

La historia nos presenta, primero, a Jindřich (Jiří Sovák) y Růženka (Dana Medřická), una pareja de investigadores de mediana edad. Ella es una eminencia en el campo de los estudios sobre sueños, mientras que él parece estar más orientado a la ingeniería -aunque nunca se estipule exactamente su labor como científico, así parece evidenciarse si tenemos en cuenta su trabajo en una fábrica y las disertaciones de sus clases-. En la fábrica en la que él trabaja se encuentra con el problema de tener que levantar un pesado motor, y pretende encontrar un modo sencillo para ello cuando comienza a leer el cómic que da título al film. Allí 
la protagonista, Jessie (Olga Schoberová), crea unos guantes antigravitacionales que podrían ser la solución que él busca. La obsesión de Jindřich lo lleva hasta el punto de soñar con el cómic esa misma noche.

Por su parte, Růženka crea un suero con el que pretende mejorar el descanso de sus pacientes evitando las pesadillas, pero lo que consigue es que los productos de esos sueños se materialicen en la realidad. Sin ser todavía consciente de este efecto secundario, aplica el suero a su marido para evitar que sueñe con Jessie. De este modo, tanto Jessie como sus enemigos, un Superman (Juraj Višný) y un Cowboy (Karel Effa), aparecerán en su piso organizando el caos por la ciudad mientras observamos cómo las autoridades y la pareja protagonista intentan detenerlos en sus persecuciones, y cómo Růženka traiciona a su marido para irse tras el Superman mientras Jindřich se queda con la bella Jessie.

Si bien el argumento es relativamente sencillo, jugando mucho a la comedia con un poco de enredo y sobre todo, a un planteamiento muy blanco en el que apenas hay sitio para el mensaje crítico con la sociedad, debemos analizar la cantidad de ideas que Vorlíček desarrolla haciéndolas patentes de un modo más intuitivo que premeditado. De entrada, el hecho de que los personajes de cómic atraviesen tres realidades -esto es, primero la del cómic, desde la que acceden a la segunda, que es el sueño de Jindřich, para finalmente invadir la realidad objetiva diegéticaresulta tremendamente interesante en cuanto a la lectura en su principio de historias enmarcadas, de mise en abyme desde el cual llega a nosotros la propia percepción de realidad que viven nuestros personajes. Una suerte de relación que se puede interpretar desde una inspiración bretoniana cuando en su Primer Manifiesto del Surrealismo decía que "creo en la futura armonización de estos dos estados, aparentemente tan contradictorios, que son el sueño y la realidad, en una especie de realidad absoluta, en una sobrerrealidad o surrealidad, si así se le puede llamar" (Breton, 1924/2009, pp. 26-27). De hecho, en cuanto a la relación del film con el surrealismo incluso autores como Owen han visto ciertos valores surrealistas, argumentando esa mezcla de realidades y la subversión aparente que conlleva su reivindicación de lo pop, comentando:

Aunque abiertamente ligera y con poco que ver con la Nueva Ola, varios aspectos del film -la parodia grotesca de las aspiraciones utópicas de la ciencia y de los intentos del estado para regular la actividad humana, la disrupción del orden 
"burgués" por parte de los tres superhéroes, y por supuesto la repetida declaración de los superhéroes "libertad para los sueños!"- puede ser perfectamente descrita como surrealista (Owen, 2013, pp. 13-14).

A pesar de las palabras de Owen, y aun aceptando esta influencia surrealista, más o menos manifiesta y presente en muchas obras coetáneas en el cine checoslovaco -sirvan los films realizados en los años 6o por Juraj Jakubisko o Jan Němec como ejemplo-, no creemos que, precisamente por lo blanco de la propuesta y de su humor debamos, ni mucho menos, plantear ¿Quién quiere matar a Jessie? como un film surrealista ni cercano a ello, sino como un mero experimento visual que recoge pinceladas de diversas fuentes para establecerse como una obra de humor. Una obra que sí tiene múltiples elementos comunes al surrealismo -esto es, el sueño, la reivindicación de la cultura popular, una muy sutil crítica a los valores burgueses-, que Hames (2010, p. 50) define como "un debate ligero sobre la libertad de la gente a soñar, cómo lidiar con las fantasías que se han vuelto reales y cómo reeducarlas" pero que pretende, más allá de buscar su propia poética o su propia visión artística imaginativa, orientarse a un público masivo y recoger esas ideas desde una simplificación absoluta en pos de que el artificio no resulte incomprensible para el espectador medio. Por esto, en adelante evitaremos destacarla como obra surrealista, aunque podamos reconocer de manera puntual esa influencia en elementos concretos, del mismo modo que la separamos, por motivos similares, de la Nueva Ola Checa.

Partiendo de esta base es importante tener en cuenta que podríamos obviar perfectamente la realidad del cómic como una que afecte al desarrollo del film, puesto que analizando la forma del mismo, los personajes que finalmente terminan en la realidad no son los del cómic sino las proyecciones mentales que Jindřich sueña. Un planteamiento que no deja de ser importante, ya que a los personajes del cómic, planos, Jindřich les da una verosimilitud y una fisicidad en su sueño que es lo que después traslada a la realidad objetiva diegética. Por tanto, obviando esa realidad tebeística, también es importante tener en cuenta que no debemos hacer lo mismo con esa capacidad de lo onírico para trasvasarse a lo real y viceversa. El film deja muy clara la separación entre ambos mundos tanto estética como narrativamente y sin embargo establece un discurso en el que la realidad del soñante influye en lo soñado y, como base narrativa, lo soñado se puede corporeizar para afectar directamente en la realidad. 
A nivel estético también existe esta separación, ya que por ejemplo en el sueño en el que Jindřich sueña con Jessie y sus villanos, el ambiente enrarecido se presenta como un decorado de cartón-piedra muy evidente, estructurándose a medio camino entre lo real y lo dibujado en el cómic hasta el punto de que en las zonas de sombra de una columna que sostiene una mazmorra podremos seguir observando las juntas de los bloques de piedra que la sostienen como líneas blancas que se destacan sobre el negro (F1). Una estética que resulta tan marcada solamente en este sueño -que es el más largo y complejo de los que se nos muestran-, ya que en el resto la estética está dentro de presentaciones más realistas por mucho que mantengan el tono onírico llegando, en el caso de una vaca con la que se hace público el experimento con el suero inventado por Růženka, a vérsela pastando desde una hamaca mientras una orquesta toca a su lado.

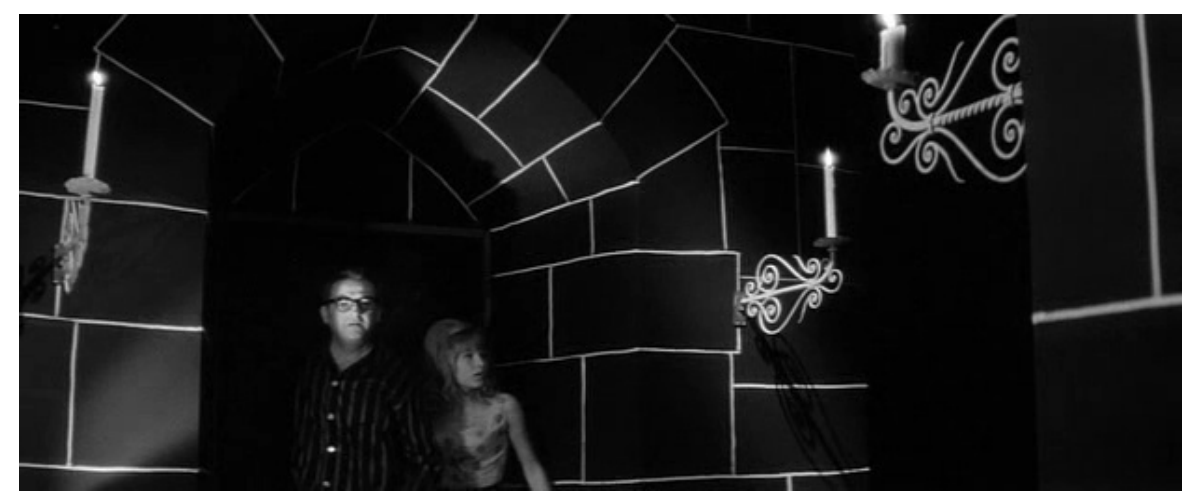

F1. Las columnas oníricas del sueño de Jindřich. Vaclav Vorlíček, ¿Quién quiere matar a Jessie?, 1966. Min. 19.13.

De entre todo el número de elementos que el film emplea para establecer esta relación entre el mundo de los sueños y el real, el más característico es precisamente éste de la incapacidad para articular palabra que presentan los personajes. Sin embargo, cabe preguntarse una cosa al analizar la narrativa de Vorlíček: ¿Los personajes salidos del sueño de Jindřich solamente hablan a través de bocadillos de texto por incapacidad o falta de entrenamiento -puesto que al final vemos que Jessie puede llegar a articular palabras-, porque el propio Jindřich los ha soñado así en un comienzo, o porque se trata de personajes salidos del cómic?

Desde nuestra óptica, teniendo en cuenta el modo en el que se comportan alejados del modelo del cómic y presentando el final con Jessie siendo capaz de 
hablar normalmente, entenderemos que solo se trata de una proyección mental del personaje plenamente humano y por tanto solo debemos comprenderlos como un elemento de su mente al igual que ocurriría si aún estuviesen en sus sueños. De hecho, el propio final, con Jessie siendo capaz de articular palabras en cuanto Jindřich se lo pide fervientemente -y entendemos que se lo imagina en su cabeza, dándole así esa nueva capacidad-, nos lleva en ese camino, con la realidad siendo imaginada y modificada por Jindřich aunque sea de manera subconsciente. Partiendo de esto, sería difícil extraer cuánto de lo que ocurre no es la mera imaginación del personaje haciendo que la realidad se modifique a su antojo, uniendo así en el film esas dos realidades y estableciendo un manifiesto, aparentemente más involuntario que voluntario, sobre la importancia de la imaginación para modificar el mundo que nos rodea. Cuestiones que parecen subyacer en el guion, pero solamente como posibilidades del mundo presentado y no como verdades absolutas en el universo diegético planteado conscientemente por sus guionistas.

\section{Utilidades del diálogo escrito en pantalla}

Sea por incapacidad de los personajes por provenir del cómic, o por impedimento porque así los ha soñado Jindřich, el aspecto más importante y sobre todo más innovador sobre el que se sustenta el film es precisamente la introducción de los diálogos de estos personajes a través de globos de texto. Mediante esta idea, Vorlíček nos presenta un concepto básico, el de la lucha de la imagen fílmica contra la palabra de una manera totalmente frontal. Del mismo modo, establece un diálogo entre el lenguaje del cómic y el del cine sonoro, recordándole al espectador de cine su pasado silente y haciendo patente, además, la irrealidad de lo narrado. Como señalan Gasca y Gubern (2001, p. 422) al respecto de los globos de texto:

Descendientes de las filacterias de la pintura medieval, perpetuadas luego por los dibujantes satiristas ingleses, los globos se convirtieron en un elemento importantísimo para activar la narratividad de los cómics primitivos, ya que las posibilidades narrativas de las historietas mudas eran muy limitadas. Más limitadas que las películas de cine mudo, cuya imagen era móvil y que utilizaban además rótulos intercalados. 
De este modo, apreciamos cómo el autor limita a unos personajes concretos ya no a una narrativa propia del pasado, sino que los sitúa en una capacidad de influir en la narrativa conjunta desde una óptica más acotada, la de un formato puramente gráfico y estático como lo es el cómic. Aplicando lenguajes de un medio en el otro, mezcla ambos mundos en una idea que subvierte la realidad, o al menos, la presentación habitual de la realidad a la que los espectadores estamos acostumbrados.

El hecho de que la película se trate de una comedia le da la libertad al creador, además, de ejecutar una suerte de giro sobre el absurdo de lo presentado. En el cómic los globos de texto se diferencian del texto narrativo y los comentarios del narrador al ser utilizados para presentar los diálogos en voz alta, los pensamientos y monólogos interiores o para presentar ruidos (Kuhn y Veits, 2015, p. 242) señalando al emisor ya sea con flechas o burbujas que forman una línea y diferenciándose entre ellos con su forma, al tener habitualmente los diálogos normales un borde continuo y definido, los pensamientos un borde con forma de nube, los susurros un borde discontinuo y los gritos y estruendos un borde con forma de sierra.

Sin embargo, los diálogos escritos que ejecutan los personajes de ¿Quién quiere matar a Jessie? no solo son empleados como en el mundo del cómic, sino que toman una corporeidad propia. Vorlíček no pretende en ningún momento hacerlos pasar por elementos que sustituyan a la voz humana como ocurría con los intertítulos del cine silente, sino que los presenta como elementos comunicativos que cobran la misma presencia física que su emisor. Una idea que no deja de tener su base en el cómic y su esencia narrativa, pues, como señala Oliveira (2018, p. 184), "en los cómics, la imagen verbal, tanto como la no verbal, asume un carácter altamente visual. Las palabras se insertan en el escenario como las figuras y, si se explora bien, tal recurso amplía las posibilidades comunicativas del medio".

De este modo, el primero de los bocadillos de texto que aparece es el de Jessie en la habitación de Jindřich preguntándole por su nombre. Aunque Jindřich oculta a la emisora para que su mujer no la vea metida en su cama, el bocadillo se mantiene flotando en el aire. Cuando Růženka entra a la habitación y pregunta extrañada por el objeto, Jindřich contesta con naturalidad que es un globo de 
texto (F2). Así, Vorlíček nos hace ver que no solamente será este el modo en el que los personajes se comuniquen y nosotros lo veamos, sino que los propios personajes que se mueven por la diégesis interior de la película también se ven obligados a leerlos. La broma no termina aquí, ya que a pesar del absurdo que pudiese ser el tener un bocadillo de texto flotando en el aire, Růženka no le da más importancia tras la explicación de Jindřich, normalizando así el asunto para el resto del film.

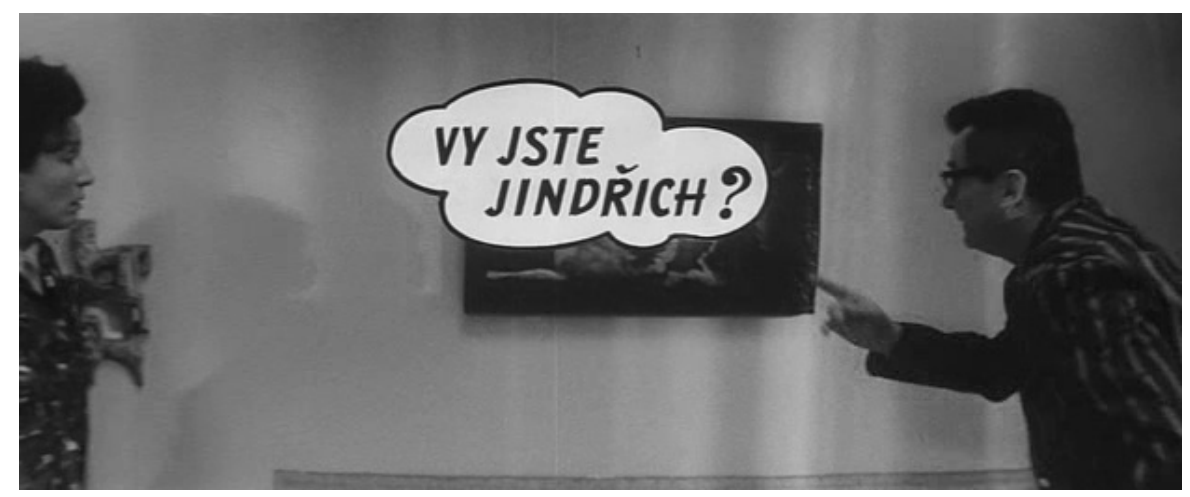

F2. El primer bocadillo que aparece, donde Jessie preguntaba a Jindřich “Usted es Jindřich?” mientras el ingeniero le explica a su mujer qué es. Vaclav Vorlíček, ¿Quién quiere matar a Jessie?, 1966. Min. 25:33.

La presencia corpórea de los globos de texto es una constante y termina por convertirse, irónicamente, en el principal vehículo para las bromas visuales de la cinta. De este modo, la presencia de lo textual deja de ser una broma de diálogo y pasa a ser parte del humor físico. Ejemplo de esto es el momento en el que Superman, lanzando cuchillos, revienta el globo de texto de su compañero Cowboy o, en la secuencia del juicio al que Jindřich es sometido por haber soñado seres tan peligrosos, el momento en el que el jurado pide girar el globo de texto en el que Jessie le dice que le ama para poder leerlo también y tomar nota (F3).

De este modo, Vorlíček juega con el espectador en un diálogo constante en el que nos hace entender que la misma realidad que vemos es la realidad extrañada y extravagante que existe en el mundo diegético. No es que nosotros observemos los diálogos de los personajes con globos de texto bidimensionales, sino que estos existen en la ficción de manera física, incluyendo su bidimensionalidad, a pesar de estar dibujados sobre el espacio filmado como efectos especiales. 


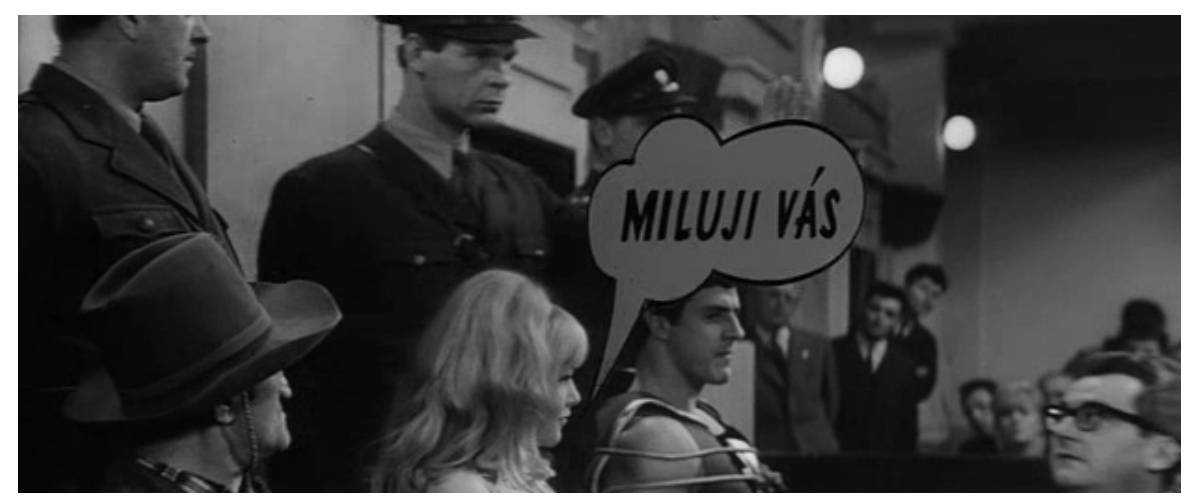

F3. El bocadillo con el que Jessie le dice a Jindřich "Le amo”, y un policía girándolo para que el jurado lo pueda ver. Vaclav Vorlíček, ¿Quién quiere matar a Jessie?, 1966. Min. 51:18.

De todos modos, y pese a la fisicidad del humor con los bocadillos, su existencia como parte textual del entramado fílmico consigue llevar también el humor por otras vías distintas. Un ejemplo de esto sería cuando, aun durante la primera adaptación de los personajes a este mundo real, el Superman intenta coger el teléfono ante la llamada del vecino pidiendo calma en el piso y al contestar suelta un globo de texto que evidentemente el vecino no puede percibir desde el otro lado de la línea. Además de para generar humor, este globo, uno de los primeros que utiliza Vorlíček en la película, sirve para ir exponiendo al espectador a las diferentes normas que tendremos que comprender, de manera no explícita, para seguir el desarrollo narrativo. Otro momento similar sobre la incomunicación provocada por este tipo de conversación que los personajes salidos del cómic se ven obligados a mantener lo podemos apreciar cuando el Cowboy sale al exterior a gritarle 'Damned’5 a un niño pequeño que está orinando en la alcantarilla por la que escapan. El niño se ve incapaz de leer y por tanto de saber qué es lo que le ha dicho el Cowboy.

Vorlíček nos expone, por diferentes vertientes, la especificidad de los lenguajes enfrentados. Por un lado, tenemos el hecho del cine como un medio al que le otorgamos una capacidad expresiva que va unida a la palabra y al diálogo por medio auditivo, alejado, una vez que el medio tuvo acceso a la reproducción sincrónica de sonido, de toda expresión escrita. Por el otro tenemos al cómic, arte también narrativa y secuencial en la que los diálogos suponen una fuerza esencial pero que no puede escapar de su reproducción en papel y por tanto de su presentación del texto por la vía escrita.

5 Condenado, en inglés en el original. 
Curiosamente, el hecho de pasar ese lenguaje escrito al lenguaje visual y sonoro del film hace que éste, lejos de perder capacidad expresiva, gane un aliado de modo que se permite un elemento visual más con el que establecer una reflexión en forma humorística y ambiental. Así, ¿Quién quiere matar a Jessie? encuentra en su estética un modo de expresión nuevo, y nos hace reflexionar sobre la presencia y la importancia del diálogo en los personajes de cine.

\section{Reflexión sobre la relación del cine y el cómic propuesta por Vorlíček}

Si nos atenemos a la definición de cómic que McCLoud (1993/1995, p. 9) plantea, "ilustraciones yuxtapuestas y otras imágenes en secuencia deliberada, con el propósito de transmitir información y obtener una respuesta estética del lector”, así como a su idea de que para el cómic es importante la combinación armoniosa de las formas de expresión escrita y dibujada (McCLoud, 1993/1995, p. 47), podemos ver que Vorlíček deja en este caso una gran laguna en su representación del cómic en la realidad diegética, escogiendo solamente el principio de los diálogos y haciendo una mera transposición de esta forma representacional del diálogo en la vida de los personajes. Sin embargo, si bien el cómic emplea de manera habitual estos globos de texto, estos son un accesorio, un "dispositivo de desesperación" (Eisner, 1985/2000, p. 26), que sirve solamente como representación del habla -y los pensamientos-, por la necesidad del autor de incorporar diálogos y no tener ningún otro medio aceptado a su alcance en un arte meramente visual como lo es el cómic, al igual que en el cine silente lo habían sido los intertítulos.

De este modo, si tenemos en cuenta que, como Eisner (1985/2000, pp. 16-24) explica, el cómic es un medio con la capacidad de narrar solamente a través de la imagen, emparentándose así con el cine silente, no es de extrañar que Vorlíček, en la simplificación propuesta sobre la idea que da frescura al humor de la cinta, haya recogido conceptos de los inicios del cine para representar situaciones excesivas en una línea de humor más slapstick. Ejemplo de esto es la destrucción del piso por parte del Superman, pero también lo son las persecuciones por tejados y calles de Praga. Si bien estos elementos parecen tener cierta lógica de cómic en una vía de la exageración de la realidad, no parecen propios del formato 
tebeístico aunque sí se originen en la realidad que vivían los personajes en el cómic creado por Saudek y que vemos, someramente, en los créditos iniciales (F4) y en lo poco que realmente se nos muestra a Jindřich leyéndolo.

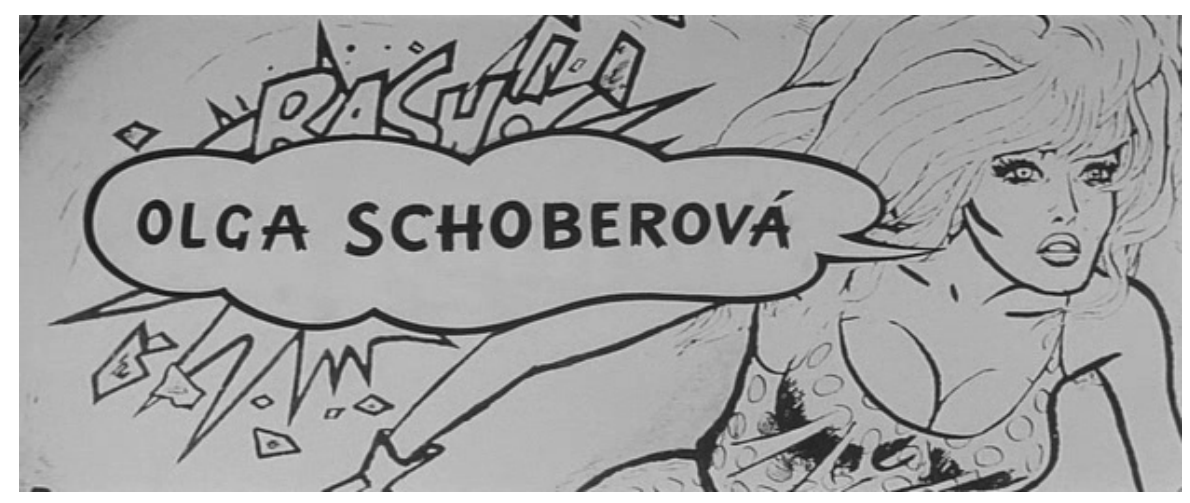

F4. La presentación del personaje de Jessie, que será interpretado por Olga Schoberová, en los créditos iniciales, dibujados por Kája Saudek. Vaclav Vorlíček, ¿Quién quiere matar a Jessie?, 1966. Min. 00:34.

Partiendo de esta reflexión, podemos decir que la realidad del cómic en el que los personajes habían sido creados en un principio se ha eliminado, optando por recoger de su mundo solamente una característica concreta que los define como personajes de cómic, aunque no estructura una fusión de las dos realidades. No obstante, esto es una cuestión que se deriva, como ya hemos dicho, del hecho de que lo que hace acto de presencia no es el personaje de cómic, sino la imagen primero comprendida y luego soñada por parte de Jindřich. En su simplificación de la idea, el guion de la película nos hace plantearnos no solamente los problemas de la fusión entre el mundo de fantasía y el real -cosa que hace de manera muy evidente-, sino que deja entrever la importancia de la comprensión del arte de manera subjetiva, y cómo esa comprensión narrativa termina por afectar a nuestra propia comprensión del mundo y de nosotros mismos. No en vano los personajes estereotipados como sexualmente atractivos que son el Superman y Jessie terminan por romper la armonía infeliz que era el hogar burgués que se nos presentaba en un inicio. Un hogar burgués que de todos modos por el tono de comedia ya se nos dejaba ver como una mera fachada de resentimiento y resignación por ambas partes de la pareja.

La sexualización de los personajes viene en cierto modo del hecho de que Kája Saudek -uno de los autores de cómic checoslovacos más importantes de la historia y hermano gemelo del fotógrafo Jan Saudek- fuese el autor de estos pequeños fragmentos de cómic y Olga Schoberová la protagonista en la que el 
dibujante se basó. La participación fue un éxito en ambas carreras y las llevó a que no mucho después, en 1969, una de las protagonistas del cómic Muriel A Andělé (escrito en 1969 pero censurado en Checoslovaquia hasta 1991) fuese basada por parte de Saudek en la explosiva rubia, que por entonces ya podía presumir de haber sido portada de la revista Playboy. Que Saudek fuese un autor principalmente de cómic para adultos muy influenciado por la cultura popular contemporánea, y que Schoberová no tardase en convertirse en una sex-symbol internacional, creando una visión sexualizada del bloque soviético en ese número de Playboy en el que sería portada, no deja de tener cierta relación con la lectura que Léger (2015, p. 70) hace del film cuando explica que "el populismo de serie B de Jessie ofrece una perspectiva de las políticas sexuales de la Nueva Ola Checa que inyecta la cuestión de la economía libidinosa dentro del marco competitivo de la Guerra Fría”.

Es destacable también el trabajo de cara a establecer unas normas sobre las cuales se crea la lógica comunicativa de los personajes en la realidad diegética. Obviamente los seres humanos normales mantienen todo el tiempo su capacidad de habla de manera totalmente natural -a excepción de un personaje que comprendemos como un doctor extranjero que está asistiendo al experimento con el que Růženka pretende demostrar su descubrimiento, de modo que para aparentar ese idioma extranjero al hablar suenan las palabras del revés-. Por su parte, los personajes del cómic establecen esos bocadillos siempre como conversación -o risa, en casos muy puntuales del Cowboy- y nunca como expresiones de sus pensamientos. Así, no permite que entremos más en su mente, como sí es habitual en el mundo del cómic.

De hecho, las acciones parecen seguir en gran medida las mismas líneas, punto por punto, que lo que ocurre dentro de los pequeños fragmentos que podemos ver del cómic diseñado por Kája Saudek. A pesar de eso, Vorlíček escapa de una rigidez absoluta en las normas, y en la parte final del film no puede evitar mostrar al perro de Jindřich hablándole a través de un globo de texto (F5). Algo que, o bien muestra que el propio autor se sitúa por encima de la historia y su posible verosimilitud dándole prioridad a la generación de humor para forzar ese momento, o que las reglas del sueño y la comunicación a través de bocadillos de texto son más flexibles en la realidad que ha creado de lo que en un principio 
podríamos suponer a través de un análisis lógico de las situaciones que se nos muestran a lo largo del film.

No deja de ser curioso, por otro lado, que sean estos tres personajes, absolutamente arquetípicos y planos, los que establecen el principio de diálogo aquí presentado. De este modo, Vorlíček elimina totalmente la necesidad de emplear frases largas, además de evitar un desarrollo excesivo de los personajes para poder establecer este juego. Frases largas que, dada la naturaleza temporal del cine frente al estatismo del cómic, impedirían un correcto desarrollo del ritmo narrativo. De hecho, en algún momento llega a presentarse algún pequeño chiste, con Jindřich parándose un tiempo excesivo a leer el bocadillo de texto y, de ese modo, pausando la acción por el mero problema comunicacional. Broma que destruiría el ritmo en caso de haberse prolongado a lo largo del resto de la cinta.

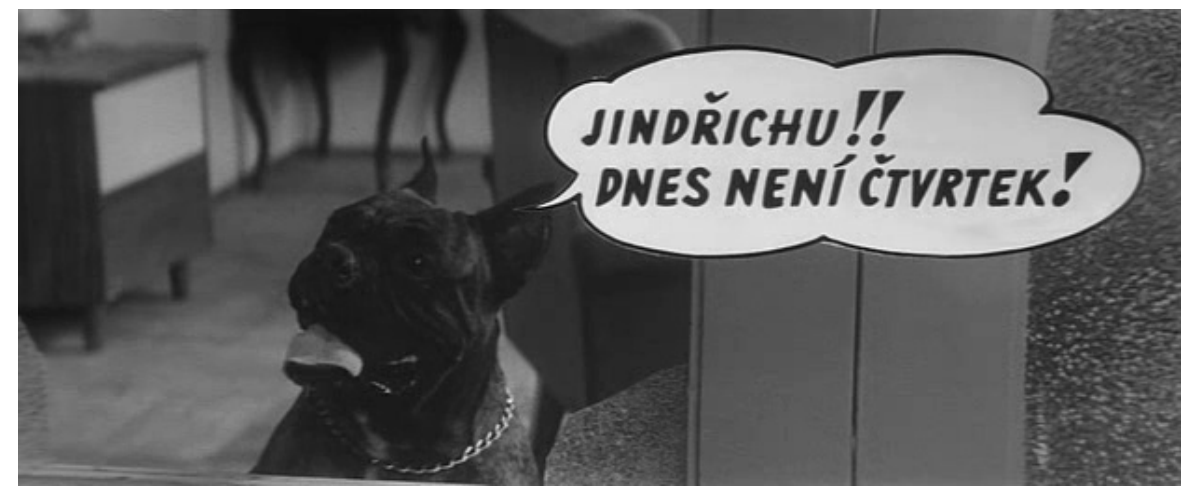

F5. El perro familiar avisando a Jindřich de que no es jueves, día habitual para hacer el amor con su mujer según se explica en el film, cuando el personaje se dispone a intimar con Jessie. Vaclav Vorlíček, ¿Quién quiere matar a Jessie?, 1966. Min. 1:16:58.

$\mathrm{Al}$ respecto de los arquetipos que representan los personajes, por un lado, tenemos a Jessie, chica explosiva cuya labor es escapar de los villanos, aunque sea capaz de ayudar en la creación de prodigios como los guantes antigravedad que tanto obsesionan a Jindřich. Por otro, tenemos a un Superman y a un Cowboy, estereotipos del cómic americano y de su cultura popular. Dos estereotipos que, como señalan Chambliss y Svitavsky (2013, p.24), representan, en el caso del vaquero, un tipo de héroe que "llevó la ley y el orden a una frontera salvaje mientras prosperaba en la libertad de allí” y en el caso del superhéroe, "resolvió los problemas provocados por el urbanismo, trayendo situaciones fantásticas a entornos familiares para crear un marco mítico para la existencia moderna” (íbid.). Sin embargo, aquí olvidan gran parte de estos rasgos como 
esencia de los géneros a los que corresponden y, paradójicamente, funcionan como antagonistas, como personajes que solamente persiguen a Jessie.

Sabemos que son malos de opereta, vacíos en sus intenciones más allá de causar el mal a la protagonista y de hecho el Superman, como personaje musculado, incluso parece bastante bobalicón en casi todo el metraje -menos en una secuencia en la que se pone a tocar el piano para dormir a un bebé, demostrando así unas sorprendentes capacidades artísticas-, resultando poco más avispado el Cowboy. Las persecuciones entre los tres, más propias, como ya hemos observado, del cine silente y de la comedia slapstick, funcionan desde esa perspectiva y escapan directamente de los cánones del cómic en los cuales, al menos, se establecerían diálogos entre los personajes mientras corren. Aquí, el guion opta por enmudecerlos y aprovechar la ventaja de la narrativa visual en movimiento que permite el cine, dejando de lado las ideas del noveno arte.

De todos modos, no debemos dejar de comentar que la influencia del cómic en ¿Quién quiere matar a Jessie? no se termina en la presencia constante de los bocadillos que sirven para que determinados personajes hablen. Vorlíček recoge también la idea de las líneas de acción que se producen en los golpes, acompañados de sonidos no realistas, para ambientar y situarnos en medio de esa mezcla de realidades que nos presenta. De este modo, aporta un mayor despliegue técnico, en el que incluso la violencia visual es remarcada por el propio lenguaje tradicional y asumible del cómic, aunque resultando en elementos que apenas aportan a nivel narrativo, sino que resultan simples artificios formales.

\section{Reflexiones finales y conclusión}

Siendo una película que nace desde la perspectiva de homenajear a la cultura popular en un entorno comercial, ¿Quién quiere matar a Jessie? se convierte irónicamente en un objeto de culto pop. Una obra que satiriza lo justo y hace que la sociedad se mire en el espejo sin sentirse agredida, consiguiendo presentarse como una comedia muy fresca. Así, si tenemos en cuenta que se trata de una película que pretende agradar al espectador desde una óptica blanca y directa, en la cual las líneas de crítica social sobrevuelan el conjunto desde perspectivas comunes a la comedia contemporánea y sin una acidez que pudiese poner en peligro el status quo o la forma de vida de la Checoslovaquia de los 60, debemos 
reconocer que sus principales aportes están en torno a la forma, no en torno al fondo, y desde ese análisis formal y estructural es desde donde hemos intentado observar las grandes cualidades de la cinta.

Las reflexiones que ofrece sobre la presencia del texto y sobre la necesidad del diálogo en el cine son múltiples, así como las posibilidades relacionales entre el séptimo y el noveno arte, probablemente las más populares de las artes narrativas del s. XX, que se influyeron mutuamente desde su nacimiento, pero que presentan diferencias, a priori, irreconciliables. De todos modos, las intenciones del director y coguionista a la hora de establecer estas reflexiones aparentan ser más casuales e intuitivas que premeditadas.

Lo original de la propuesta, el hecho de que elementos propios del mundo del cómic como lo son los globos de texto se hagan presentes en la narrativa cinematográfica, nos hace conscientes de la importancia del diálogo hablado y sincrónico conseguido a través de la llegada del sonido al cine. La forma escogida y el conflicto que genera en nuestras expectativas a la hora de ver y escuchar una película nos obligan a establecer primero una postura de defensa por la sorpresa que supone y después una comprensión profunda sobre las diferencias de ambas artes.

Un film a reivindicar que, de haber sido producido en un país con mayor proyección cinematográfica mundial o de haber sido capaz de introducirse en los libros de historia a través de la Nová Vlna, habría llegado a suponer una piedra angular en las relaciones entre el cine y el cómic gracias a su originalidad a la hora de plantear dicho acercamiento.

\section{Referencias bibliográficas}

Beaty, B. (2011). Introduction. Cinema Journal 50:3, primavera 2011, 106-110. DOI: 10.1353/cj.2011.0022.

Breton, A. (2009). Manifiesto del Surrealismo. En J. J. Pauvert (ed.) Manifiestos del Surrealismo (Trad. A. Bosch) (pp. 15-61). Madrid: Visor Libros. (Año de publicación original: 1924).

Burke, L. (2015). The Comic Book Film Adaptation: Exploring Modern Hollywood's Leading Genre. Jackson, MS: University Press of Mississippi.

Chambliss, J. C. y Svitavsky, W. L. (2013). The Origin of the Superhero: Culture, Race, and Identity in US Popular Culture, 1890-1940. En J. C. Chambliss, 
W. L. Svitavsky y T. Donaldson (Eds.), Ages of Heroes, Eras of Men: Superheroes and the American Experience (pp. 6-27). Newcastle: Cambridge Scholars Publishing.

Davis, B. (2017). Movie Comics: Page to Screen/Screen to Page. New Brunswick: Rutgers UP.

Eisner, W. (2000). Comics \& Sequential Art. Tamarac, FL: Poorhouse Press. (Año de publicación original: 1985)

Fontaine Rousseau (2014). Batman: The Movie de Leslie H. Martinson. 24 Images, n. 170 (diciembre 2014-enero 2015) 20-20.

García, S. (2010). La Novela Gráfica. Bilbao: Astiberri.

Gasca, L. y Gubern, R. (2001). El Discurso del Comic. Madrid: Cátedra.

Hames, P. (1985). The Czechoslovak New Wave. Berkeley: University of California Press.

Hames, P. (2010). Czech And Slovak Cinema: Theme and Tradition. Edinburgo: Edinburgh University Press.

Kuhn, M. y Veits, A. (2015). Narrative Mediation in Comics: Narrative Instances and Narrative Levels in Paul Hornschemeier's The Three Paradoxes. En D. Birke y T. Köppe (Eds.), Author and Narrator: Transdisciplinary Contributions to a Narratological Debate (pp. 235-261). Berlin/Munich/Boston: De Gruyter. 10.1515/9783110348552.235, $10.1515 / 9783110348552$.

Lefèvre, P. (2007). Incompatible Visual Ontologies? The Problematic Adaptation of Drawn Images. En I. Gordon, M. Jankovich y M. P. McAllister (Ed.), Film and Comic Books. Jackson, MS: University Press of Mississippi.

Léger, M. J. (2015). Drive In Cinema: Essays on Film, Theory and Politics. Bristol: Intellect.

Mareš, P. (2014). The Kind Millionaire, Lemonade Joe and Superman. On Czech Film Parodies. Images. The International Journal of European Film, Performing Arts and Audiovisual Communication, 14: 23 (Enero 2014), 1524.

McCloud, S. (1995). Cómo se Hace un Cómic: El Arte Invisible (trad. Enrique Abulí). Barcelona: Ediciones B. (Año de publicación original: 1993).

Oliveira, M. C. (2018). Quadrinhos, Literatura e a Intertextualidade. Literartes, 8:1, 181-194. DOI: 10.11606/issn.2316-9826.literartes.2018.145827.

Owen, J. L. (2011). Avant-garde to New Wave. Czechoslovak Cinema, Surrealism and the Sixties. Nueva York: Berghan Books.

Smith, C. (2015). Motion comics: the emergence of a h ybrid medium. Writing Visual Culture, 7, 1-23.

Williams, B. (2017). Comic-book artifice: Olga Schoberová's hyper-femininity in Václav Vorlíček's Who Wants to Kill Jessie? Studies in Eastern European Cinema, 8:2, 146-159, DOI: 10.1080/2040350X.2017.1304691. 